\title{
Analysis of Shijiazhuang Urbanization Effect on the Ecological Environment
}

\author{
Dianru Wang, Siyuan Deng \\ Shijiazhuang economic college, \\ Shijiazhuang, China
}

\begin{abstract}
Urbanization needs the sustained and healthy economic and social development as the premise, the coordinated development and healthy development cannot do without the ecological environment. The coordinated development of ecological environment requires scientific and effective control and prevention on the changes of regional land use, water resources, and atmospheric environment. This paper analyzes the development status of the current situation of urbanization and ecological environment in Shijiazhuang city and discusses the effect of stress on the ecological environment of Shijiazhuang city: urbanization stress effect on the water resources, urbanization stress effect on land resources, and urbanization stress effect on the atmospheric environment.
\end{abstract}

Keywords-Shijiazhuang city; urbanization; ecological environment; stress effect

\section{INTRODUCTION}

Shijiazhuang city Hall 71st executive meeting adopted the "guidance on promoting the urbanization of Shijiazhuang city." "Hebei economic development report" Blue Book (2014) also pointed out: in 2013, Hebei province urbanization rate was $48.12 \%$, while $85 \%$ for developed countries, Hebei will need about 19 years to catch up with [1]. The Shijiazhuang city's urbanization rate was $55.72 \%$, which about 30 percentage points lower than that of developed countries. When compared with Beijing and Tianjin cities, the level of urbanization in Shijiazhuang city is also lower. Therefore, we must accelerate the urbanization construction, develop county economy, different industry structure, open market system, and establish a good ecological environment, and enhance the level of sustainable development of a city, to release the urbanization development potential. Urbanization needs the sustained and healthy economic and social development as the premise, the coordinated development and healthy development cannot do without the ecological environment. The coordinated development of ecological environment requires scientific and effective control and prevention on the changes of regional land use, water resources, and atmospheric environment.

\section{THE URBANIZATION DEVELOPMENT SITUATION OF SHIJIAZHUANG CITY}

\section{A. The Level of Urbanization Increase Steadily and Go into the Rapid Development Stage}

Although Shijiazhuang urban history is shorter, the development is faster. Seen from Table I, the level of urbanization in Shijiazhuang has continued to increase, rising from $14.59 \%$ in 1990 to $55.72 \%$ in 2013. The average annual growth rate is $7.07 \%$, average annual growth rate is nearly 1.2 percentage points higher than the province's average growth rate, 1.05 percentage points higher than the national average growth rate. Before 2000, Shijiazhuang's urbanization rate is too low, lower than the national and Hebei provincial city level. Since 2005, Shijiazhuang has entered a rapid urbanization stage.

TABLE I. THE LONGITUDINAL CONTRAST OF SHIJIAZHUANG CiTY’s URBANIZATION LEVEL.

\begin{tabular}{|c|c|c|c|c|c|c|c|}
\hline \multirow{2}{*}{ Region } & \multicolumn{6}{|c|}{ The Urbanization Level(\%) } & \multirow{2}{*}{$\begin{array}{c}\text { The Average } \\
\text { Annual Growth } \\
\text { Rate }\end{array}$} \\
\hline & 1990 & 1995 & 2000 & 2005 & 2010 & 2013 & \\
\hline Shijiazhuang & 14.59 & 17.81 & 24.55 & 42.62 & 48.62 & 55.72 & $7.07 \%$ \\
\hline Hebei & 14.37 & 17.07 & 26.08 & 37.69 & 45 & 48.12 & $5.8 \%$ \\
\hline The nation & 15.53 & 29.04 & 36.22 & 42.99 & 49.95 & 53.70 & $6.02 \%$ \\
\hline
\end{tabular}

Note: Data from the statistical yearbook of Shijiazhuang [2], "Hebei province economy yearbook" [3], and China statistical yearbook [4].

\section{B. The Unbalanced Development of Urbanization}

Although the overall level of urbanization in Shijiazhuang city has entered the stage of rapid development, but the regional differences of urbanization is obvious, the specific performance differences exist between the city center and the surrounding counties and cities. The level of urbanization in Shijiazhuang is characterized by decreasing progressively from the city center to outwards. In 2013, the urbanization rate of Shijiazhuang city was $55.72 \%$. The city land area is 456 square kilometers, which accounts for only $2.87 \%$ of the total area, but the city's urban population accounted for $50.09 \%$ of the total population. City area urbanization rate 
averaged $94.7 \%$. The urbanization rates in the rest of the periphery counties and cities are below the average level in the city. Zhengding, Luancheng county, Gaocheng, Luquan city that these four satellite cities' urbanization is relatively high, which was about $40 \%$. The land area of the rest 13 counties accounted of the city is $82.9 \%$, but the urban population is only $33.15 \%$ of the urban population, the urbanization level is lower than $30 \%$. Among these counties, Zanhuang county is the lowest that the urbanization level is only $19.96 \%$ [2].

\section{Urbanization and Suburbanization Exist Together}

At present, Shijiazhuang city is still in the stage of development of city agglomeration, but the phenomenon of suburbanization has been produced. Suburbanization development in Shijiazhuang city differs from that of western developed countries, which performance for the agglomeration and diffusion effect of industry and population at the same time. On the one hand, due to the Shijiazhuang city development is still in the rapid development stage, the center area is still maintained a strong ability to attract factors and keeping the benign direction. Along with the advancement of urbanization, the industrial structure is going the adjustment, urban central district industry especially the labor-intensive, heavy pollution industry began to move to the suburbs, centrality strong commercial, financial, and other tertiary industry go agglomeration in the central city. At the same time, Shijiazhuang promotes a variety of paid land use system, invest a lot of money for reconstruction of "village in city." These have enhanced the modernization function in central area of the city. Therefore, the city center district is not only appearing in the "hollow," but more prosperity. On the other hand, because the industrial and residential relocation, construction and the building of the Eastern Development Zone, which was quickly developed in the suburban area, so, there are some new industrial zone in the suburban area.

\section{Urban Spatial Structure is a Single Core-periphery Model}

Currently, spatial structure in Shijiazhuang area presents a single core-periphery model. Shijiazhuang urban construction maintains a certain speed by spreading along the traffic line, constantly improves the agglomeration process and strengthen it, gives full play to the regional production and consumption center functions, has formed a single core structure in the whole space. Peripheral counties and center city are keeping vertical linkages and formed the core of next level in their own area. The structure model is developed over the years in Shijiazhuang area. From the current situation, the polarization effect is far greater than the diffusion effect, which will promote the overall development in Shijiazhuang city. However, to a large extent, this model also bring obstacles to the economy development of county areas, it will make the differentiation of the dual structure, and will make the city developing in the future lack of support from restricted area.

\section{THE PRESENT SITUATION OF ECOLOGICAL ENVIRONMENT IN SHIJIAZHUANG CITY}

\section{A. The Status of Water Resources of Shijiazhuang}

Shijiazhuang city is located in the Haihe River Basin that was the country's most serious water shortage. The quantity of water resources per capita is only 244 cubic meters, which is one of the most serious water shortage city and even in the world. For a long time, due to geographical constraints, $90 \%$ water of Shijiazhuang depends on groundwater. Reasonable exploitation of groundwater in Shijiazhuang (non-agricultural) every year is $140-150$ million cubic meters. Shijiazhuang city in recent years has an average of 3.36 billion cubic meters of water, of which $85 \%$ depends on groundwater, including plain groundwater resources 2.546 billion cubic meters. The overdraft strength of the city's groundwater reached $175 \%$, and the plain area groundwater reached $214 \%$. The excessive dependence on groundwater and serious over exploitation of groundwater made the water environment seriously damaged, which produce the series problems such as the deterioration of water quality and water resources on the geological, ecological, and environmental problems. Groundwater overdraft make groundwater resources decrease, the groundwater level continued to decline, the bearing capacity of groundwater is greatly reduced, which produce the potential hazard of the water resources security [5].

\section{B. The Situation of Land Resources in Shijiazhuang City}

According to 2012 statistics, Shijiazhuang city has an area of 15,848 square kilometers and a permanent population of 10.2798 million people, of which the urban area is 456 square kilometers and with a population of 2.87 million. With the development of society and economy, the situation of Shijiazhuang land use changes constantly, with the arable land reduction and construction land area increased. From 2000 to 2010, Shijiazhuang land area reduced from 74,204 hectares to 70,104 hectares, a decrease of 4100 hectares. Among these, 93\% of the arable land transferred into construction land, assigned to the waters and the forest land area is less and less, which is not conducive to the sustainable development of land productivity and the ecological environment construction $[2,6]$.

\section{Air Resources of Shijiazhuang City}

In recent years, with the development of urbanization and industrialization, atmospheric pollution is increasingly serious in Shijiazhuang city. According to the analysis of statistical classification of the main air pollution, Shijiazhuang air pollution sources can be generalized into three aspects: fuel combustion, industrial processes, and transportation. According to the statistic data of atmospheric pollution, the proportion of the above three aspects are $70 \%, 20 \%$, and $10 \%$, respectively. In the direct combustion of the fuel, the number of air pollutant emissions accounted for about $96 \%$ of the total fuel combustion emissions, including the number of dust, 
emissions of $\mathrm{SO}_{2}, \mathrm{NO}_{\mathrm{X}}$, and $\mathrm{CO}$ accounted for fuel combustion emissions are respectively 99\%, 93\%, 81\%, and $97 \%$. Although air pollution emissions from industrial production process is only $1 / 5$ of total air pollution emissions, but due to the relative concentration, so making the mining areas or local air environment affecting seriously.

\section{SHIJIAZHUANG URBANIZATION EFFECT ON THE ECOLOGICAL ENVIRONMENT}

\section{A. Urbanization Stress Effect on the Water Resources}

Urbanization effects on water resources are mainly in two aspects. On the one hand, it makes the urban water demand rising and increasingly makes significant contradiction between supply and demand; On the other hand, It makes pollution of surface water and groundwater, the pollution mainly comes from industrial liquid waste, waste water, city life sewage, municipal waste accumulation seeping liquid, as well as precipitation atmospheric pollution.

From the first half of 2014 water resources bulletin, the water supply of Shijiazhuang city was 1.794 billion
M3, water is needed for the 2.404 billion M3 [5], per capita water resources amount to 258 M3 which was less than $1 / 8$ of the national per capita water resources. According to the quantitative evaluation standard in the world, Shijiazhuang city belongs to the absolute poor water district. In recent years, the Shijiazhuang city vigorously develop township and village industry and industrial transfer, many rural surplus labor force flow from rural to urban, which improves the urban population growth rate and population size. As can be seen from Table II, the urbanization development and water resources have a certain relationship in Shijiazhuang city. With the improvement in city urbanization, the total water consumption increasing gradually, and with water demand increasing, the corresponding stress effect on water resources will continue to increase. Along with the urbanization rate increased by 1 percentage points, total water consumption increased by an average of 4.5833 million M3, the improvement of urban population growth and urbanization rate has become one of the important reasons for the increase of the total water consumption in the city.

TABLE II. SHIJIAZHUANG CITY URBANIZATION AND WATER RESOURCES.

\begin{tabular}{|c|c|c|}
\hline Year & 2005 & 2012 \\
\hline The urbanization rate(\%) & 42.62 & 52.82 \\
\hline The total water consumption(100 million M3) & 31.4247 & 31.8922 \\
\hline
\end{tabular}

Note: Data from the Shijiazhuang water resources bulletin [5, 6].

\section{B. Urbanization Stress Effect on Land Resources}

On one hand, Shijiazhuang accelerated the pace of the urbanization, which will increase agglomeration population of the region in the long run, and accordingly creating favorable conditions for agricultural production intensification and modernization, and improve the utilization efficiency of cultivated land resources. But on the other hand, the rapid growth of urban population makes the per capita land space reduced and a lot of agricultural land be transferred to non-agricultural land, which changes the structure of the land use between urban and rural areas and make contradiction between the construction land expansion and arable land protection and the contradiction between the urban protection and farmers, and also makes the urban ecological environment capacity changing. First, from the overall perspective, the urban and rural construction land and cultivated land are the main land use types, both for the total area of Shijiazhuang city 75.77\%. Second, in 2007-2013, cultivated land area decreased gradually, with a total decrease of 4000 hectares, accordingly, urban and rural construction land increased significantly in contrast. The elasticity of city construction land to the economic development is 0.6, namely with economic growth $1 \%$, city construction land will increase by $0.6 \%$; the elasticity of city construction land to urbanization is 0.39 , namely, with the level of urbanization increased per $1 \%$, city construction land will increase $0.39 \%$ [7]. The latter elasticity is less than the former, the city construction land increase was mainly due to economic development, and the urbanization caused little effect.

\section{Urbanization Stress Effect on the Atmospheric Environment}

Urbanization brings atmospheric pollution to the environment. For example, there are the heat island effect, the ozone layer, acid rain, inversion layer, the greenhouse effect, and the phenomenon such as photochemical smog. Urbanization stress effect on atmospheric environment mainly depends on the city's population density, industrial structure, pollution control measures, and the greening land layout and so on. After the comprehensive treatment of environmental pollution for many years, the situation of air pollution in Shijiazhuang city has been improved year by year. In 2010, Shijiazhuang city, the number of days of two level and two level above reached to 319 days, in which air environmental was being light pollution level. But compared with other cities, Shijiazhuang city belongs to a severe air pollution city. In 2007, in the integrated pollution index of Shijiazhuang city was 18th to the last 
days in national 47 key cities. In 2011, the air quality in Shijiazhuang city is in the medium level in the 11 cities in the province, more comprehensive pollution index of Shijiazhuang city is in the province's fifth [8]. Stress effects on the atmospheric environment of Shijiazhuang city are mainly because the coal smoking pollution and the heavy industrial structure and higher resource intensive and energy intensive industries, and lack of corresponding facilities, etc.

\section{ACKNOWLEDGMENTS}

The research work was supported by Soft Science Key Project of Hebei Provincial Grant No. 13454215D and Social Science Fundation of Hebei Provincial under Grant No. HB14GL029.

\section{REFERENCES}

[1] Tao Lianghu, China's Low-carbon Economy. Beijing University Press, Beijing, 2010.

[2] Hebei Province Statistical Bureau, Hebei Statistical Yearbook (2013). China Statistics Press, 2013.

[3] Hebei Provincial Statistical Bureau, Hebei Economic Yearbook (2013). China Statistics Press, 2013.

[4] China Bureau of Statistics, Chinese Statistical Yearbook, Chinese Statistics Press, 2013.

[5] Water Resources Department of Hebei Province, Hebei Provincial Water Resources Bulletin, 2013.

[6] Land and Resources Department of Hebei Province, Bulletin of Land Resources in Hebei Province, 2013.

[7] Z.A. Zhao, Measurement and Analysis of the Relationship between Economic Development and City Construction Land. Population, Resources and Environment in China, 2011.

[8] Shijiazhuang Environmental Protection Bureau, The Environment Bulletin of Shijiazhuang City, 2002-2010. 